\title{
Factors Influencing the Attendance of Patients with Type II Diabetes to Retinopathy Screening Series; a Primary Care Based Study in Bahrain
} Dr. Afaf Abdulmonem $\mathrm{Ali}^{1}$, Dr. Mona Abdulmonem $\mathrm{Ali}^{1}$, Dr. Rabab Malalla ${ }^{1}$, Dr. Khatoon Shubbar ${ }^{1 *}$, Dr. Khaldoon Al Roomi $^{2}$

${ }^{1} \mathrm{BSc}, \mathrm{MD}$, Irish and Arab Board Certified in Family Medicine

${ }^{2} \mathrm{BSc}, \mathrm{MD}$, Department of Family \& Community Medicine, Dean of AGU

\begin{tabular}{ll}
\hline DOI: $10.36348 /$ sjmps.2019.v05i11.006 & | Received: 01.11.2019| Accepted: 08.11.2019| Published: 14.11 .2019 \\
*Corresponding author: Dr. Khatoon Shubbar &
\end{tabular}

Abstract

Background: Diabetes is a highly prevalent chronic disease and Bahrain is ranked amongst the top ten. Diabetes has many complications. Retinopathy caused by diabetes if considered number one leading cause of blindness world wild. This study explore the factors influencing the uptake of the Digital Retinopathy Screening Programs (DRGP). Methods: Five of the Primary Care centers in the country providing the (DRSP) have been visited on daily basis for two weeks in row and patients attending for the test have been questioned, defaulters were called and questioned through the phone for the causes. Results: A total of 367 type II DM patients were enrolled in the study with a (42.5\%) are within the age range of 50-59. $75.2 \%$ of the sample attended for the screening and were questioned and the remaining non attendees were questioned through the phone. A Comparison between the characteristics and reasons behind attendance and non attendance amongst the two groups was conducted statistically by SPSS using Chi Sequare test and Fisher's exact test. Results using P-Value showed that the major reasons for non attending the appointments are forgetting the appointment, ignorance, neglect, some special circumstances like sickness or travel and miscommunication between patients and staff or physicians. While on the other hand, reminders and physician recommendations have show to be of a positive influence over patients' attendance. Conclusion: It is quiet essential to work on strategies that decrease the percentage of defaulters and improve the uptake of an important screening program such as the DRSP. Reminder systems, Improvement of the communications between patients and health care provider and increasing physicians' recommendations to enhance patients' awareness are all modifiable factors that can influence best on improving such service.

Copyright @ 2019: This is an open-access article distributed under the terms of the Creative Commons Attribution license which permits unrestricted use, distribution, and reproduction in any medium for non-commercial use (NonCommercial, or CC-BY-NC) provided the original author and source are credited.

\section{INTRODUCTION}

The prevalence of Diabetes Mellitus (DM) for all age-groups worldwide was estimated to be $2.8 \%$ in 2000 and $4.4 \%$ in 2030. The total number of people with diabetes is projected to rise from 171 million in 2000 to 366 million in 2030 [1]. DM is highly prevalent among both sexes in member states of the WHO Eastern Mediterranean Region. Its prevalence in these countries ranges from $3.5 \%$ to $30 \%$ [2]. The prevalence of Type 2 DM was reported as $30 \%$ among the Bahraini population in 1998 [3]. in 2007, around $14.3 \%$ of the population in Bahrain suffers from DM with prevalence ranking $5^{\text {th }}$ compared to other countries worldwide [4].

Diabetic retinopathy (DR) is one of the main complications of diabetes accounting for approximately $5 \%$ of all blindness globally [5]. In Bahrain, a cross sectional survey in 1997 found that DR is responsible for $6 \%$ of the cases of visual disability [6].

The practical guidelines for management of diabetes in Bahrain recommends annual screening for diabetic retinopathy starting from the time of diagnosis for type 2 Diabetic patients [7]. A local study done in 2007 to report the results of Bahrain DR screening program found that $25.3 \%$ of the patients had nonproliferative diabetic retinopathy and $1 \%$ had proliferative retinopathy changes [8].

Although diabetic retinopathy screening (DRS) programs are available in Bahrain, there are still diabetic patients who are not receiving any form of such a screening. Patients who do not attend diabetic eye screening were found to have increased risk of developing sight-threatening diabetic retinopathy [9]. 
This study is conducted to explore the factors influencing the attendance of adult patients with type II DM for retinopathy screening in order to identify the characteristics of the attendees and non-attendees. The aim is to develop strategies that improve the uptake of the screening program and hence early detection and possible management to prevent blindness.

\section{METHODS}

Digital Retinopathy screening (DRS) program in Bahrain is freely available in most Primary Care Center, covering the five governorates of Bahrain. There are twenty four primary health centers; one of which in each governorate receives the referrals to the DRS.

Diabetic patients undergo this examination annually and they can either be referred from the general clinic or the diabetic clinic with intraocular pressure (IOP) measurements and vision documented in the referral paper. Appointments are then given for patients.

On Each day, the appointment Lists are printed and patients who attend are interviewed. (IOP + Vision) are being measured while other Laboratory data are obtained from the laboratory computer system.

A cross-sectional study was conducted in which characteristics of attendees and none attendees were compared. For those non attendees, contact numbers were traced from the registry computer system and patients received a phone call from a researcher to inquire about the causes of non-attending. In addition, patients answered the questionnaire over the phone. (IOP + Vision) were not obtained in these cases.

After examination is being completed on those attendees, images of the retinas are saved to a Software system and at the end of the day are taken to Salmaniya Medical Complex (SMC); the main secondary hospital in the country; attached with the Copy of the referral paper to all patient who undergone the screening on that day to be reviewed by an Ophthalmologist. For those who show normal Retinal imaging, papers were filed back. If imaging shows any pathological changes in the retina; patients then will be scheduled for a follow up appointment with an Ophthalmologist in SMC.

The inclusion criteria was all patients with type II diabetes aged 20 years and older referred from primary health care doctors for DRS. Patients who refused to participate, those with communication or language barrier, non-respondents or with contact number problems were excluded from the study population.

Over the period of the study, 547 patients were identified. Among the 322 attendees; 276 satisfied the criteria and were included in the study. In comparison, among the 225 non-attendees; 91 patients were identified as they met the criteria of inclusion.

The natures and objectives of the study were explained to the participants and consent forms were obtained from all patients.

Questionnaires were coded and entered into computer. Data were analyzed using the SPSS program. Chi- Square and Fisher-exact tests were used to identify the significant factors which are related to attendance by comparing both groups. P- Value was considered significant if $\leq 0.05$.

\section{RESULTS}

A total number of 367 type 2 diabetic patients were enrolled in the study. Of those, (75.2\%) had attended the screening test.

The age of patients ranged from 20 to 94 years, and (42.5\%) are within the age range of 50-59. Female constitute $(55 \%)$ of the sample. The majority were Bahrainis $(82.6 \%)$. Almost half of the sample $(53.9 \%)$ were graduates of secondary school or college. However, most of the participant were unemployed (Domestics $43.6 \%$, retired $16.1 \%$. unemployed $0.5 \%$ ). Smokers constitute $26.2 \%$. It has been noticed that most of the referral were from the Diabetic clinic $(71.7 \%)$ as compared to the general clinic, and $(63.5 \%)$ have done the test before. When comparing the demographic data between attendees and non-attendees, there was no significant difference between the two groups Table-1.

The medical characteristics of participants showed that around half of the referral $(51.8 \%)$ were for patients with duration of diabetes of less than 5 years. Those who use insulin were (16.3\%). Regarding Diabetes complications, (3.8\%) have nephropathy, $(7.6 \%)$ neuropathy, and $(14.7 \%)$ with eye problems. However, (55.3\%) have high blood pressure and (73.7\%) have dyslipidemia. Diabetes control was identified using Fasting Blood Sugar (FBS) and Glycated Hemoglobin $\left(\mathrm{HbA}_{1 \mathrm{C}}\right)$. Uncontrolled FBS was in $(70.9 \%)$ of the participants, and poor control of $\mathrm{HbA}_{1 \mathrm{C}}$ in $(42.3 \%)$. However, there is no significant difference between the attendees and non attendees.

Most participants $(62.9 \%)$ claimed that they received diabetic information from their medical team, (95.9\%) think that diabetes can affect eyes, (91.3\%) think it may lead to vision loss, $(44.1 \%)$ did not receive any recommendation from their physician to have a regular eye test, though $(94.8 \%)$ think that its important. Most patients think that Diabetic retinopathy always comes with symptoms $(66.8 \%)$ and $(86.4 \%)$ think that it can be treated if detected early (Table-1). 
Afaf Abdulmonem Ali et al; Saudi J Med Pharm Sci, Nov. 2019; 5(11): 956-960

There was no differences in the knowledge between the attendees and non-attendees towards diabetic retinopathy, except that $(88.4 \%)$ of the attendees think that DM retinopathy can be treated if detected early as compared to $(80.2 \%)$ of non-attendees, and this difference is significant ( $p$-value 0.048). Surprisingly, $100 \%$ of the non-attendees think that DM can affect eyes as compared to $(94.6 \%)$ of the attendees (p-value 0.027) (Table-1).

Factors which discouraged diabetic patients from attending the screening test are outlined in (Table $2 \& 3$ ). unavailability of transport was considered as a factor preventing patients attendance among (32.7\%) of the total sample, followed by busy schedule (29.2\%) forgetting the appointment (28.6\%) and ignorance/neglect in (23.7\%). However, comparing between attendees and non attendees using Chi-square test or Fisher's test, a significant value was for forgetting the appointment (p-value 0.000), miscommunication (p-value 0.000) and ignorance ( $\mathrm{p}$ value 0.031 ) (Table-2). On the other hand, many factors were mentioned to encourage Diabetic patients to attend the screening test, the most mentioned were: patients knowledge (44.7\%), physician recommendation $(42.5 \%)$ and self care of own health $(38.4 \%)$. However, comparing between attendees and non attendees using chi-square or Fisher test, a significant value was for the presence of remainders ( $\mathrm{p}$-value 0.000 ) and physician recommendation (p-value 0.009) (Table-3).

Table-1: Patients Knowledge towards Diabetic Retinopathy

\begin{tabular}{|c|c|c|c|c|c|}
\hline & & $\begin{array}{l}\text { Total\% } \\
(\mathrm{N}=367)\end{array}$ & $\begin{array}{c}\text { Attendee } \\
\% \\
(\mathrm{n}=276) \\
\end{array}$ & $\begin{array}{c}\text { Non } \\
\text { attendee\% } \\
(n=91)\end{array}$ & $\begin{array}{c}\text { Chi- } \\
\text { Square } \\
\text { p-value }\end{array}$ \\
\hline \multirow{2}{*}{$\begin{array}{l}\text { Have you received diabetic information from } \\
\text { your physician? }\end{array}$} & Yes & $62.9 \%$ & $63.4 \%$ & $61.5 \%$ & \multirow[t]{2}{*}{0.749} \\
\hline & No & $37.1 \%$ & $36.6 \%$ & $38.5 \%$ & \\
\hline \multirow[t]{2}{*}{ Do you think that DM can affect the eyes? } & Yes & $95.9 \%$ & $94.6 \%$ & $100.0 \%$ & \multirow[t]{2}{*}{$0.027^{\mathrm{a}}$} \\
\hline & No & $4.1 \%$ & $5.4 \%$ & $0.0 \%$ & \\
\hline \multirow[t]{2}{*}{ Do you think that DM can lead to vision loss? } & Yes & $91.3 \%$ & $90.9 \%$ & $92.3 \%$ & \multirow[t]{2}{*}{0.689} \\
\hline & No & $8.7 \%$ & $9.1 \%$ & $7.7 \%$ & \\
\hline \multirow{2}{*}{$\begin{array}{l}\text { Does your physician recommend you to have } \\
\text { regular Diabetic Retinopathy? }\end{array}$} & Yes & $55.9 \%$ & $56.2 \%$ & $54.9 \%$ & \multirow[t]{2}{*}{0.840} \\
\hline & No & $44.1 \%$ & $43.8 \%$ & $45.1 \%$ & \\
\hline \multirow{2}{*}{$\begin{array}{l}\text { Do you think that regular Diabetic Retinopathy } \\
\text { Exam is important? }\end{array}$} & Yes & $94.8 \%$ & $95.3 \%$ & $93.4 \%$ & \multirow[t]{2}{*}{$0.585^{\mathrm{a}}$} \\
\hline & No & $5.2 \%$ & $4.7 \%$ & $6.6 \%$ & \\
\hline \multirow{2}{*}{$\begin{array}{l}\text { Do you think that Diabetic patients needs to do } \\
\text { this eye exam more than once in a year? }\end{array}$} & Yes & $67.3 \%$ & $65.2 \%$ & $73.6 \%$ & \multirow[t]{2}{*}{0.138} \\
\hline & No & $32.7 \%$ & $34.8 \%$ & $26.4 \%$ & \\
\hline \multirow{2}{*}{$\begin{array}{l}\text { Do you think that Diabetic retinopathy always } \\
\text { comes with symptoms? }\end{array}$} & Yes & $66.8 \%$ & $65.9 \%$ & $69.2 \%$ & \multirow[t]{2}{*}{0.564} \\
\hline & No & $33.2 \%$ & $34.1 \%$ & $30.8 \%$ & \\
\hline \multirow{2}{*}{$\begin{array}{l}\text { Do you think DM retinopathy if detected early } \\
\text { can be treated? }\end{array}$} & Yes & $86.4 \%$ & $88.4 \%$ & $80.2 \%$ & \multirow[t]{2}{*}{0.048} \\
\hline & No & $13.6 \%$ & $11.6 \%$ & $19.8 \%$ & \\
\hline
\end{tabular}

Table-2: Factors preventing patients from attending retinopathy screening program among patients with type 2 diabetes in PHC in Bahrain

\begin{tabular}{|c|c|c|c|c|}
\hline & $\begin{array}{c}\text { Total } \\
\% \\
(\mathrm{~N}=367)\end{array}$ & $\begin{array}{c}\text { Attendee } \\
\% \\
(\mathbf{n}=276)\end{array}$ & $\begin{array}{c}\text { Non } \\
\text { attendee\% } \\
(\mathbf{n}=91)\end{array}$ & $\begin{array}{c}\text { P- } \\
\text { value }\end{array}$ \\
\hline Forgetting the appointment & $28.6 \%$ & $18.8 \%$ & $58.2 \%$ & 0.000 \\
\hline Unavailability of transport & $32.7 \%$ & $35.1 \%$ & $25.3 \%$ & 0.082 \\
\hline Busy schedule, No free time & $29.2 \%$ & $26.8 \%$ & $36.3 \%$ & 0.085 \\
\hline Patient is unaware of the importance of screening & $18.5 \%$ & $20.7 \%$ & $12.1 \%$ & 0.068 \\
\hline Inability to leave work & $16.1 \%$ & $17.4 \%$ & $12.1 \%$ & 0.232 \\
\hline Ignorance and neglect & $23.7 \%$ & $26.4 \%$ & $15.4 \%$ & 0.031 \\
\hline Fear from results & $8.2 \%$ & $8.3 \%$ & $7.7 \%$ & 0.847 \\
\hline Special Circumstances (sickness, travel) & $12.8 \%$ & $10.9 \%$ & $18.7 \%$ & 0.053 \\
\hline Unsuitable or far appointment & $6.3 \%$ & $5.1 \%$ & $9.9 \%$ & 0.100 \\
\hline Distance & $3.0 \%$ & $2.9 \%$ & $3.3 \%$ & $0.738 *$ \\
\hline Screening is Not available in the same HC or area & $2.5 \%$ & $2.9 \%$ & $1.1 \%$ & $0.461^{*}$ \\
\hline Waiting Time & $1.4 \%$ & $1.8 \%$ & $0.0 \%$ & $0.338^{*}$ \\
\hline Effect of Drops & $2.5 \%$ & $2.2 \%$ & $3.3 \%$ & $0.696^{*}$ \\
\hline $\begin{array}{l}\text { Patient was not Informed about the availability of the } \\
\text { screening by the Medical team }\end{array}$ & $1.1 \%$ & $1.4 \%$ & $0.0 \%$ & $0.576^{*}$ \\
\hline Crowd and disorganization & $2.2 \%$ & $2.5 \%$ & $1.1 \%$ & $0.685^{*}$ \\
\hline If patients having no Symptoms or Complains & $2.7 \%$ & $2.5 \%$ & $3.3 \%$ & $0.714^{*}$ \\
\hline Miscommunication & $2.7 \%$ & $0.4 \%$ & $9.9 \%$ & $0.000^{*}$ \\
\hline Patient doing the test in private hospital & $0.8 \%$ & $0.7 \%$ & $1.1 \%$ & $0.576^{*}$ \\
\hline Others & $3.3 \%$ & $4.0 \%$ & $1.1 \%$ & $0.308^{*}$ \\
\hline
\end{tabular}


Afaf Abdulmonem Ali et al; Saudi J Med Pharm Sci, Nov. 2019; 5(11): 956-960

Table-3: Factors encouraging the attendance to retinopathy screening program among patients with type 2 diabetes in PHC in Bahrain

\begin{tabular}{|l|c|c|c|c|}
\hline & $\begin{array}{c}\text { Total \% } \\
(\mathbf{N = 3 6 7})\end{array}$ & $\begin{array}{c}\text { Attendee \% } \\
(\mathbf{n = 2 7 6})\end{array}$ & $\begin{array}{c}\text { Non attendee\% } \\
(\mathbf{n = 9 1 )}\end{array}$ & P-value \\
\hline Physician recommendation & $42.5 \%$ & $46.4 \%$ & $30.8 \%$ & 0.009 \\
\hline Patients knowledge & $44.7 \%$ & $46.7 \%$ & $38.5 \%$ & 0.168 \\
\hline Patient having visual symptoms & $17.4 \%$ & $17.4 \%$ & $17.6 \%$ & 0.967 \\
\hline history of personal + family history & $7.1 \%$ & $7.2 \%$ & $6.6 \%$ & 0.833 \\
\hline Fear of Loss of vision & $8.7 \%$ & $8.7 \%$ & $8.8 \%$ & 0.978 \\
\hline Self Care of Own health & $38.4 \%$ & $38.8 \%$ & $37.4 \%$ & 0.811 \\
\hline Reminders & $6.8 \%$ & $4.0 \%$ & $15.4 \%$ & 0.000 \\
\hline Physician Communication & $1.9 \%$ & $1.1 \%$ & $4.4 \%$ & $0.067^{*}$ \\
\hline Availability of the test in the same HC or area & $1.6 \%$ & $1.4 \%$ & $2.2 \%$ & $0.640^{*}$ \\
\hline Organized appointments and good service & $2.2 \%$ & $2.2 \%$ & $2.2 \%$ & $1.000^{*}$ \\
\hline Family Encouragement & $1.9 \%$ & $1.8 \%$ & $2.2 \%$ & $0.685^{*}$ \\
\hline Availability of transportation & $.5 \%$ & $.7 \%$ & $.0 \%$ & $1.000^{*}$ \\
\hline Availability of the test in the afternoon or evening & $.5 \%$ & $.4 \%$ & $1.1 \%$ & $0.435^{*}$ \\
\hline Media advertisement & $2.2 \%$ & $2.5 \%$ & $1.1 \%$ & $0.685^{*}$ \\
\hline Availability of treatment & $1.6 \%$ & $2.2 \%$ & $.0 \%$ & $0.343^{*}$ \\
\hline Others & $2.2 \%$ & $1.8 \%$ & $3.3 \%$ & $0.415^{*}$ \\
\hline
\end{tabular}

\section{DISCUSSION}

DM has become a worldwide public health problem and all reports indicates that this epidemic will increase rather decrease in the future [7]. Retinopathy is a major but preventable complication of DM with incidence reported to account for 5 percent [3]. One of the main factors to prevent DM eye complications is early detection [6]. This study was set to find out the rate of attendance and factors which contribute to poor attendance for DRS Service It appears from our studies that the number of attendees shows $75.2 \%$ only.

The study results indicated that age, gender, education level and knowledge of patients about the disease were not related to the attendance of patients to DRS test. Neither the chronicity of illness showed any influence on the attendance. On the contrary, the literature showed variable results regarding these factors which would appear to be related to doctors' factors.

It is well known that good glycemic control when achieved can help prevent and slow down the diabetic complications on the long run [7]. In this study $\mathrm{HbA}_{1} \mathrm{c}$ was used as a tool to measure glycemic control among participants and when compared between the two groups, it showed no significant relation on the attendance. One study showed that patients with poor $\mathrm{HbA}_{1} \mathrm{c}$ control showed low uptake of the screening test [12]. The same study, reported poor uptake of the test among smokers and those with poor Blood Pressure Control, this can be explained by the neglectance to one health [12], while these factors didn't show any significant relation among the two studied groups in our study maybe because patients were instructed and recommended by physicians to attend regardless of being aware of the importance and the aim behind the screening test.
In the current study, forgetting the appointments and the absence of reminders in relation to the long periodic gap between the day of registry to the day of the test, have resulted in a negative uptake of patients. These two factors were not found nor mentioned in other studies.

Studies reported that physician endorsement of the screening program were increasing the uptake of the screening tests $[10,13]$. In this study, results showed significant relation between physician recommendation and increase uptake of the screening test.

Effect of the eye drops on patients have also been studied as it was found in one study to negatively affecting the test uptake due the discomfort and unfavourable sensation while being unaware of it as a side effect [10], while in this study was found to be insignificantly related which might be explained by patients awareness about the effect of drops from previous visits (as $63.5 \%$ of our sample did the test before).

\section{CONCLUSION}

Although diabetes retinopathy was found to be prevalent in patients with diabetes mellitus in Bahrain, it is gratifying that most of the factors studied and were significantly influencing the uptake of the screening program are modifiable. Hence, preventive strategies can be easily built to improve the attendance of patients with type II DM to the DRSP in primary care and hopefully lower the number of defaulters. Reminder systems, Improvement of the communications between patients and health care provider and increasing physicians' recommendations to enhance patients' awareness are all modifiable factors that can influence best on improving such available services. 


\section{REFERENCES}

1. Wild, S., Roglic, G., Green, A., Sicree, R., \& King, H. (2004). Global prevalence of diabetes: estimates for the year 2000 and projections for 2030. Diabetes care, 27(5), 1047-1053.

2. Diabetes by WHO, regional office for the eastern Mediterranean / from www.emro.who.int/healthtopics/diabetes_Retrieved in September 2011

3. Al-Mahroos, F., \& McKeigue, P. M. (1998). High prevalence of diabetes in Bahrainis: associations with ethnicity and raised plasma cholesterol. Diabetes care, 21(6), 936-942.

4. Diabetes Prevalence-country Rankings 2010 by International Diabetes Federation, Retrived from www.allcountries.org/ranks/diabetes_prevalence_ country_ranks.html in September 2011.

5. Prevention of Blindness and Visual Impairment by WHO, from http://www.who.int/blindness/causes/priority/en/in dex6.html Retrieved in September 2011.

6. Ahmed, A., Al-Alawi, E., \& Fatiha, B. (2002). National Survey of causes of visual disability in Bahrain. Saudi Journal of Ophthalmology, 16(4), 279-87.

7. Bahraini Guidelines for DM2 by $\mathrm{MOH}, \mathrm{PHC}$, Bahrain. Published in June 2008.

8. Al-Kobaisi, N. (2009). Diabetic retinopathy screening using digital retinal camera, Bahrain from Journal of the Bahrain Medical Society, 21(1).

9. Forster, A. S., Forbes, A., Dodhia, H., Connor, C., Du Chemin, A., Sivaprasad, S., ... \& Gulliford, M. C. (2013). Non-attendance at diabetic eye screening and risk of sight-threatening diabetic retinopathy: a population-based cohort study. Diabetologia, 56(10), 2187-2193.
10. Dervan, E., Lillis, D., Flynn, L., Staines, A., \& O'Shea, D. (2008). Factors that influence the patient uptake of diabetic retinopathy screening. Irish journal of medical science, 177(4), 303-308.

11. Rabha Salman, M. D., \& Med, F. (2004). Screening of Diabetic Retinopathy in Primary Care. Bahrain Medical Bulletin, 26(1).

12. Leese, G. P., Boyle, P., Feng, Z., Emslie-Smith, A., \& Ellis, J. D. (2008). Screening uptake in a well-established diabetic retinopathy screening program: the role of geographical access and deprivation. Diabetes Care, 31(11), 2131-2135.

13. Wang, D., Ding, X., He, M., Yan, L., Kuang, J., Geng, Q., \& Congdon, N. (2010). Use of eye care services among diabetic patients in urban and rural China. Ophthalmology, 117(9), 1755-1762.

14. Lewis, K., Patel, D., Yorston, D., \& Charteris, D. (2007). A qualitative study in the United Kingdom of factors influencing attendance by patients with diabetes at ophthalmic outpatient clinics. Ophthalmic epidemiology, 14(6), 375-380.

15. Maberley, D. A., Koushik, A., \& Cruess, A. F. (2002). Factors associated with missed eye examinations in a cohort with diabetes. Canadian journal of public health, 93(3), 229-232.

16. Schoenfeld, E. R., Greene, J. M., Wu, S. Y., \& Leske, M. C. (2001). Patterns of adherence to diabetes vision care guidelines: baseline findings from the Diabetic Retinopathy Awareness Program. Ophthalmology, 108(3), 563-571.

17. Van Eijk, K. N. D., Blom, J. W., Gussekloo, J., Polak, B. C. P., \& Groeneveld, Y. (2012). Diabetic retinopathy screening in patients with diabetes mellitus in primary care: Incentives and barriers to screening attendance. Diabetes research and clinical practice, 96(1), 10-16. 